\title{
INTEGRATING PRODUCTION AND MAINTENANCE PLANNING AS AN ELEMENT OF SUCCESS AT THE TACTICAL LEVEL: A FUZZY CONTROL THEORY APPROACH
}

\author{
${ }^{1}$ Ronald DÍAZ CAZAÑAS, ${ }^{2 *}$ Daynier Rolando DELGADO SOBRINO, \\ ${ }^{1}$ Estrella María DE LA PAZ MARTÍNEZ, ${ }^{2}$ Peter KOŠŤÁL, \\ ${ }^{2}$ Andrea MUDRIKOVÁ
}

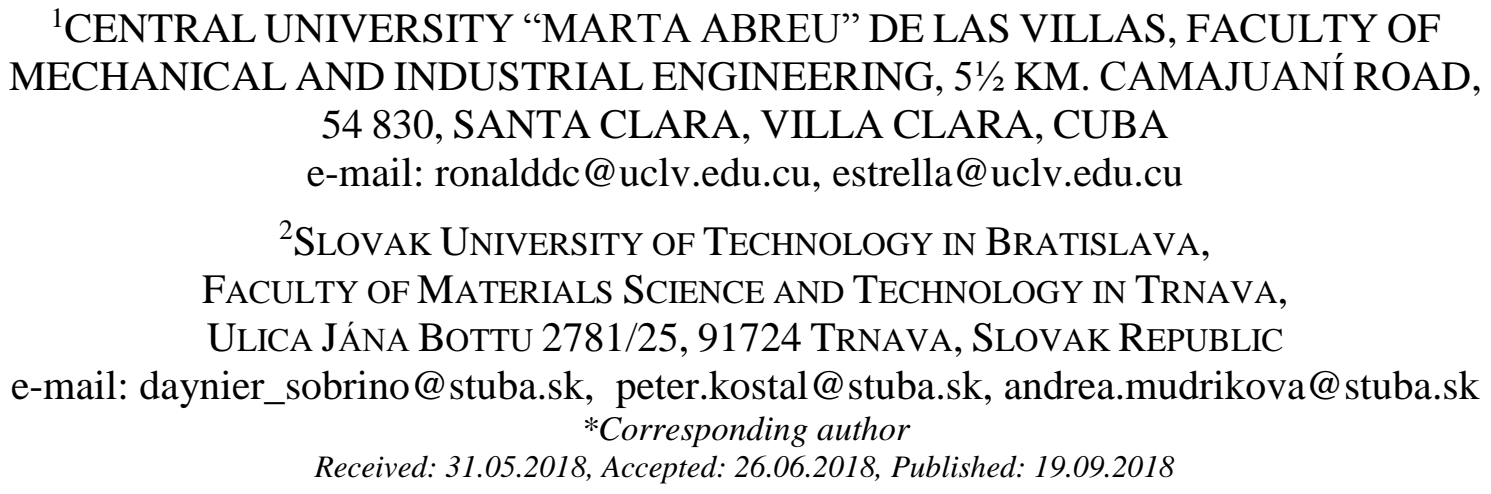

\begin{abstract}
This contribution focuses on the topic of the Production-Maintenance integration at the tactical level and what it presents to the correct functioning and success of companies. For these purposes, a general framework for the integration of production and maintenance planning at the tactical level is introduced and described within this paper. It considers the key elements from the Value Analysis, Fuzzy Control and the Reliability-Centered Maintenance theories and implements them into the context of an existing method for selecting maintenance strategies. The proposal mainly focuses and addresses the definition of $1 /$ the roles played by the fixed assets that do really add value to the production system, 2/ the best maintenance strategy for each asset, and also addresses $3 /$ the modifications that, may be needed in the tactical production plan due to potential capacity problems in the maintenance subsystem.
\end{abstract}

Key words

Production planning, maintenance planning, assignment of maintenance type, integration, asset/equipment, Fuzzy Control Theory

\section{INTRODUCTION}

In terms of planning, the process of integrating different departments, functions and/or processes of a production facility has been an area of significant complexity in the states of the 
art and practice. A clear example of this is the Production-Maintenance planning integration problem, as recognized by several authors (1-6). Despite much has been done in this respect, at present this duo keeps posing a serious challenge for planners, and thus remarkable gaps and discordances remain between the independent processes of decision making taking place in both subsystems at the same time. Clear examples illustrating such gaps and supporting all to this problematic situation are: (a) repetitive failures in meeting the production programs due to maintenance interventions, (b) numerous defects in productions as a result of a poor performance of production assets caused by the not implementing and executing maintenance plans, (c) insufficient control of the maintenance-associated costs, and (d) poor understanding and not technically or properly justified delays of maintenance interventions for prioritizing other productive activities, etc.

However, many of these gaps and concrete problems could be improved via a proper planning integration of production and maintenance activities. Since in the literature one can find just few authors who have addressed this issue from a somehow similar or even close perspective, a framework that contributes to integration of the subsystems of Production and Maintenance in the mid-term or tactical level, and that leads a process of analysis and improvement of the fundamental factors that have an influence on this matter, presents itself as a scientific problem identified in the states of the art and practice, and thus the main puzzle to be solved within this contribution.

To take this challenge, the paper proposes a general framework for the mentioned integration that focuses on two main aspects: 1) enhancing the capacity of the Maintenance subsystem to add value to the Production one and, 2) orienting the tactical planning of the Production subsystem, so that the projection of its objectives is made with the needed objectivity based on the capacity that the Maintenance subsystem can deliver for the time horizon of the planning.

\section{MATERIALS AND METHODS}

\section{Main characteristics of the framework}

The framework starts by establishing the system of maintenance that fits each asset/equipment the best. This is done by considering the value that the functions of the fixed assets add to the objectives pursued in Production/Operations. The framework then continues to analyze if the preliminary maintenance strategy is feasible by balancing the real availability of resources and the ones that would be needed to realize the preventive tasks. If some of these tasks could not be executed, then the impact this causes in the Operation management subsystem $(\mathrm{OM})$ is determined and quantified, what helps deciding if changes in its planning should or should not be carried out. At the end, all this allows for creating a system of maintenance focused on the Operation objectives. It is a simultaneous planning of the OM taking into account the Maintenance capacity to back up the Production objectives.

\section{The steps of the framework}

Fig. 1 shows the graphical representation of the framework and its steps. It is important to point out that the proposal is intended to either analyze the existing systems or design the new ones, hence its steps and structure.

\section{Planning}

This step refers to the planning and organization of the necessary resources to carry out the project. It includes the creation of work team and the group of experts to assess decisions. This 
is to be done carefully following the statistical relation between the size of the group of experts and the desired quality or level on confidence for the study (7).

\section{Analysis of the decisions in the $O M$}

The main decisions that of the Production/Operations subsystem are to be identified here, mainly those that keep a greater relation with the performance of the subsystem of Maintenance, either because the results that are obtained from these decisions are determined by the performance of Maintenance, or because such decisions constitute elements to consider at the moment to design this last subsystem.

\section{Analysis of the functions/role of the assets}

From interviews with the personnel of Production and Maintenance, the work team is to identify the productive functions the fixed assets play in their operational context.

\section{Analysis of the value of the assets}

Here the efficacy of the assets functions is evaluated, it allows examining their effectiveness, and then define strategies for their preservation; the deciding criterion here is achieving the production goals and not preserving the functions. For these purposes, the application of the informative and the analysis and evaluation phases of the Analysis of Value methodology are considered enough, for further information authors suggest to see (8).

\section{Elimination or improvement of functions}

This is to be done and supported by technologists and maintenance personnel. Changes proposed in the operation standards can lead to either the adoption of the improved maintenance policy or the redesign of equipment.

\section{Definition of the adding value functions}

The functions remaining here are the ones remaining indeed add value to the subsystem of Production.

\section{Determination of key functional failures that impact the decisions in Operations}

Herein the work team conducting the study will have to rely on the knowledge of the selected experts, as well as on the criterion of the maintenance personnel.

\section{Determination of failure modes}

If the proper causes are identified, it guarantees that time and efforts are not wasted treating the symptoms instead of the causes.

\section{Definition of the Hierarchy of the failure modes}

The impact of the failure modes on the OM decisions is determined, subsequently also the relative importance of each decision, and finally, conjugating both of these, the hierarchical order of each failure is established. 


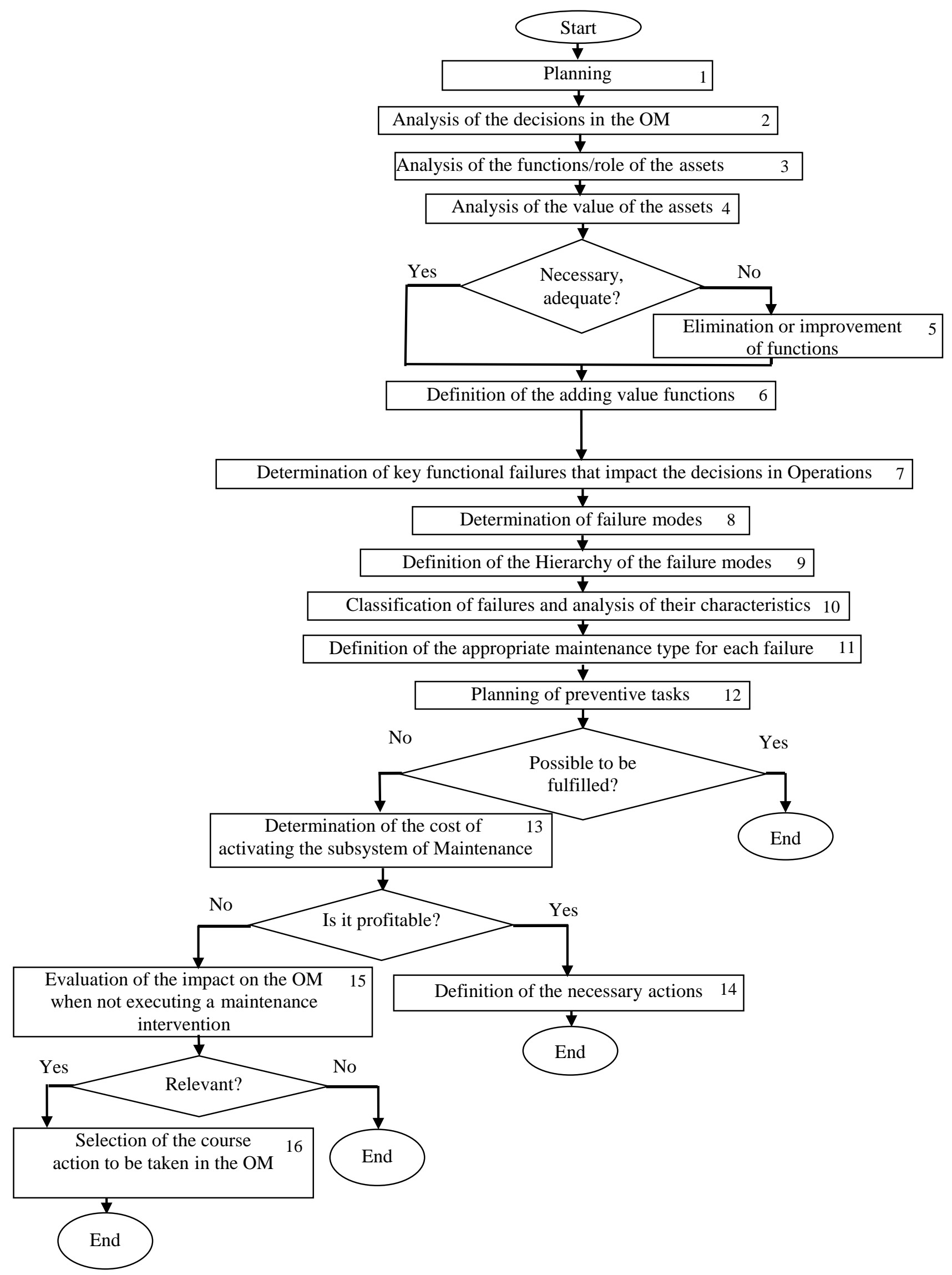

Fig. 1 General Framework for the integration of production and maintenance planning at the tactical level. Source: Self-elaboration. 
The Ordinal Diffuse Linguistic Modeling is used for determining the impact of the failure modes. This an approach that has given good results to model the always-present uncertainty in the qualitative evaluations of experts $(9,10)$. In this case a scale of seven levels is proposed for the evaluation. These levels represent linguistic terms related to diffuse numbers with a pertinence function of the triangular type; the associated scale appears in Fig. 2:

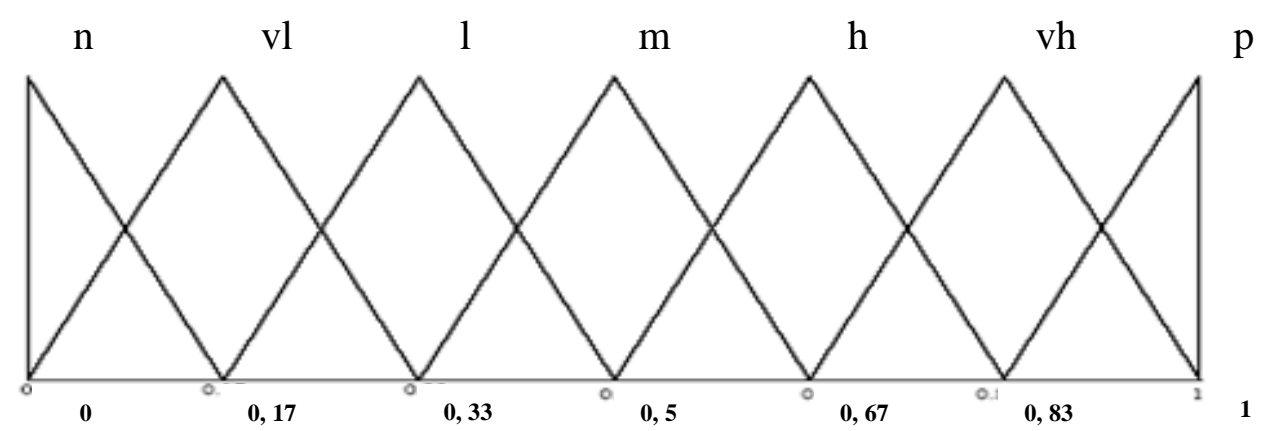

Fig. 2 Linguistic terms used in the indicators' evaluation. Source: (11)

Where:

n: null, vl: very low, l: low, m: medium, h: high, vh: very high, p: perfect

The weight or relative importance of the decisions considered can be obtained by means of several methods, e.g.: the Simple Arrangement method (11). In order to conjugate the failure modes impact and the relative importance of the OM decisions, the well-proven and known Weighted Sum method will be applied as appears in expression 1.

Cri $=\sum_{j=1}^{n}\left(a_{2 i j} * w_{j}\right)$

Where:

Cri: criticality of the failure mode $\mathrm{i}$

$a_{2 i j}$ : term $\mathrm{a}_{2}$ corresponding to the triangular diffuse number that is associated to the linguistic term that characterizes the evaluation of the failure mode $i$ on the decision $j$, given by the experts, using the scale defined in Fig. 2.

$w_{j}$ : weight of decision $\mathrm{j}$

$\mathrm{n}$ : total of analyzed decisions

The ordering of the failures in the hierarchy will be obtained from the $\mathrm{C}_{\mathrm{ri}}$ value, these will be ordered in a descendent way.

10. Classification of failures and analysis of their characteristics

Failures will be classified according to the following elements appearing in (12): Randomness (r); Facility of detection (fd); Frequency (f) and Regularity (r).

\section{Definition of the appropriate maintenance type for each failure}

Table 1 summarizes a method published by (12) for the assignment of types of maintenance to failure modes. This authors conjugates and balance the importance of the assets within the productive process and the characteristics of the failure itself. Based on this method, there have been initially defined three types of maintenance, i.e.: Predictive Maintenance (I), Preventive Maintenance (II) and Corrective Maintenance (III)

The Class factor defines the weight of the failure mode within the productive process. In this case the ones classified as class A are those of greater importance. This is because these have a greater impact on economic and environmental factors, also in the security of the personnel. On the contrary, those of class $\mathrm{C}$ have little influence in the mentioned variables. This methods besides states that for a failure mode that classifies as class $\mathrm{A}$, besides is periodic 
and of easy detection, the first pick is that of assigning it to the Predictive maintenance (I), if it were not possible, then to the Preventive one (II), and finally to the Corrective one (III) as the least feasible option.

\begin{tabular}{|l|c|c|c|c|}
\hline \multicolumn{4}{|c|}{ Table 1: Method used to select the most suitable maintenance system to each asset } \\
\hline Class & $\begin{array}{l}\text { periodic method-easy } \\
\text { detection }\end{array}$ & $\begin{array}{l}\text { periodic method- } \\
\text { difficult detection }\end{array}$ & $\begin{array}{l}\text { less frequent- } \\
\text { random method }\end{array}$ & $\begin{array}{l}\text { very frequent- } \\
\text { random method }\end{array}$ \\
\hline A & I,II,III & II,I,III & I,III & I,III \\
\hline B & I,II,III & II,III & III & I,III \\
\hline C & II,III & III & III & III \\
\hline
\end{tabular}

Source: Slightly modified based on (12).

Besides, it was then also considered that the concepts of blurred subgroups could be applied to failure mode classification, according to the class, and its characteristics, in accordance with the method stated in Table 1. The need of this approach comes from the fact that in real life, it is considered less coherent with the reality to define exact limits between classes, because when analyzing the impact of the failure on the productive process, the environment and the people, it may happen, for example, that it is not $100 \%$ A class, being able to be included, simultaneously, in classes A and B, in accordance with the intensity of its impact. This applies as well with the characteristics of the failure because, Randomness (r), Facility of detection (fd), Frequency (f) and Regularity (r) also constitute diffuse terms.

These considerations were incorporated to the method shown in Table 1. Thus now, modeling the failure mode pertinence to each of the three possible classes, as well as to its characteristics will be done also taking into consideration the concepts of linguistic variable and theory of the blurred control with exponents 2 and $1 / 2$ for the quantifiers "very" and "more or less" respectively, and the classic operator of negation, see also for this (13). In consequence it may happen that a same failure mode belongs, with different intensity (pertinence degrees), to more than one type of maintenance. This reflects in a better and more complete way, the situations we frequently see in Industry.

Then, stating that a failure mode belongs to the subgroup of failures modes where, for example, preventive maintenance is to be assigned first, see Table 1, depending on the following condition:

In case that the failure mode belongs to the class $A$ and is periodic and of difficult detection; or in case that it belongs to class $\mathrm{B}$ and it is, also, periodic and of difficult detection; or in case that it belongs to class $\mathrm{C}$ and is periodic and of easy detection, see Table 1 again.

All this can be mathematically represented by means of the linguistic variable concepts and the theory of the blurred control:

$\mu_{I I}^{M f}=T^{*}\left[T\left[\mu_{A}^{M f}, T\left[\mu_{p}^{M f}, 1-\mu_{f d}^{M f}\right]\right], T\left[\mu_{B}^{M F}, T\left[\mu_{p}^{M f}, 1-\mu_{f d}^{M f}\right]\right], T\left[\mu_{C}^{M f}, T\left[\mu_{p}^{M f}, \mu_{f d}^{M f}\right]\right]\right]$

The belonging of the failures modes to the corrective maintenance would be modeled according to:

$$
\begin{aligned}
\mu_{I I I}^{M f} & =T^{*}\left[T\left[\mu_{B}^{M f}, T\left[\mu_{a}^{M f}, 1-\mu_{f}^{M f}\right]\right], T\left[\mu_{C}^{M F}, T^{*}\left[T\left[\mu_{p}^{M f}, 1-\mu_{f d}^{M f}\right], T\left[\mu_{a}^{M f}, 1-\mu_{f}^{M f}\right],\right.\right.\right. \\
& \left.\left.\left.T\left[\mu_{a}^{M f},\left(\mu_{f}^{M f}\right)^{2}\right]\right]\right]\right]
\end{aligned}
$$

Where:

$\mu_{I I}^{M f}$ :( Degree of pertinence) of the failure mode $M f$ to the system of maintenance II (preventive maintenance) 
$\mu_{I I I I}^{M f}:$ ( Degree of pertinence) of the failure mode $M f$ to the system of maintenance III (medium repair)

$T^{*}$ : triangular T-conorm used within the theory of the blurred control to model the logic operator or.

$T$ : triangular T-norm used within the theory of the blurred control to model the logic operator and.

$\mu_{A}^{M f}$ : (Degree of pertinence) of the failure mode $M f$ to class A.

$\mu_{B}^{M f}$ :( Degree of pertinence) of the failure mode $M f$ to class B

$\mu_{C}^{M f}:$ ( Degree of pertinence) of the failure mode $M f$ to class $\mathrm{C}$

$\mu_{a}^{M f}$ : (Degree of pertinence) of the failure mode $M f$ to the diffuse subgroup made up of the random failure modes.

$\mu_{f}^{M f}$ : (Degree of property) of the way of $M f$ failure the diffuse subgroup made up of frequent failures modes

$\mu_{f d}^{M f}$ : (Degree of pertinence) of the failure mode of $M f$ to the diffuse subgroup of the failure mode easy to detect.

$\mu_{p}^{M f}:$ (Degree of pertinence) of the failure mode $M f$ to the diffuse subgroup made up of the periodic failures modes

Within this research the minimum and maximum operators will be used to model the T-norm and the T-conorm respectively.

\section{Planning of preventive tasks}

It must settle down the time between preventive interventions and the necessary resources. For the first one, a policy can be followed to maximize availability or to guarantee a minimum threshold of reliability, in correspondence with the objectives of Operations. From these criteria, and considering the distribution the variable "Mean time between Failures" follows, the "optimal" time between preventive interventions can be calculated (14). In case that the plan of preventive maintenance can be fulfilled at the $100 \%$, the procedure gets to an end; otherwise it would go to the following step.

\section{Determination of the cost of activating the subsystem of Maintenance}

If the subsystem of Maintenance cannot completely accomplish certain tasks, the cost to provide the required capacity will be estimated. Then a cost-benefit analysis defines its feasibility.

\section{Definition of the necessary actions}

Actions are defined to undertake the preventive works that could not be previously carried out by the lack of capacity.

If it were not advisable to activate the subsystem of Maintenance to be either carried out by own means or outsourcing, then the step 15 would follow.

\section{Analysis of the impact of not executing a maintenance intervention on the $O M$}

For this, it is necessary to first specify the relationship between the condition of equipment and its availability, with regard to the variables that characterize the performance of Operations. This will allow quantifying the risk of not fulfilling of the production goals due to the possible deterioration of the condition of the equipment, or its availability, as a consequence of the absence of a preventive maintenance task. The authors of (15) propose a model to determine the impact of good practices of the General Motors Company on the costs, quality and deliveries; this model can work as an inspiration for the development of this step. In the impact of not executing the maintenance were to significantly affect the Operations decisions, then the step 16 follows. 


\section{Selection of the course action to be taken in the $O M$}

The decisions of Operations that are affected by the non-execution (partial or total) of the maintenance task will have a redefinition of their goals. This might mean, for example, to readjust dates of delivery in case of a significant deterioration of the availability; quality plans, in case of affectations in the condition of the equipment, among others.

\section{CONCLUSIONS AND FURTHER RESEARCH ISSUES}

The present paper addressed a key gap in the states of the art and practice regarding the integration of production and maintenance planning at the tactical level. To tackle the issue, a scientifically-based framework was proposed that considered elements from the Value Analysis, the Reliability-Centered Maintenance and the Fuzzy Control Theory, putting them together in the context of an existing method for selecting maintenance strategies. Further research ideas will keep improving the results achieved so far and publish them including several practical applications the authors have been able to carry out over these years.

\section{Acknowledgement}

This paper was supported by the KEGA-021STU-4/2018 Project of Development of a laboratory for the design and maintenance of production systems supported by the use of Virtual Reality. This support is gratefully acknowledged.

\section{References:}

1. MUCHIRI, P. and PINTELON, L. 2011. Development of maintenance function performance measurement framework and indicators. International Journal of Production Economics. 2011. 131. 295-302. 0925-5273.

2. AGHEZZAF, E. H., JAMALI, M.A. and AIT-KADI, D. 2007. An integrated production and preventive maintenance planning model. European Journal of Operational Research. 2007. 181. 679-685. 0377-2217.

3. NAJID, N., ALAOUI, M. and MOUHAFID, A. 2010. An integrated production and maintenance planning model with time windows and shortage cost. International Journal of Production Research. 2010. 10. 1 - 24.0020-7543

4. ACHERMANN, D. 2008. Modelling, Simulation and Optimization of Maintenance Strategies under consideration of Logistic Processes. A dissertation submitted to the Swiss Federal Institute of Technology Zurich for the degree of Doctor Technical Sciences. 2008. Diss. ETH. No. 18152

5. AGHEZZAF, E. H. and NAJIB, M. 2008. Integrated production planning and preventive maintenance in deteriorating production systems. Information Sciences. 2008. 178. 3382-3392. 0020-0255.

6. JIN, X., LI, L. and NI, J. 2009. Option model for joint production and preventive maintenance system. International Journal of Production Economics. 2009. 119. 347-353. 0925-5273.

7. Alfonso LLANES, A. 2009. Procedimiento para la asistencia decisional al proceso de tercerización de la ejecución del mantenimiento. Tesis presentada en opción al grado científico de doctor en ciencias técnicas. Universidad Central de Las Villas, Santa Clara, Cuba.

8. MILLES, L. D. 1972. Techniques of value analysis and engineering. Publisher: McGraw Hill, USA,

9. PORCEL GALLEGO, C. 2005. Sistemas de acceso a la información basados en información lingüistica difusa y técnicas de filtrado. Tesis presentada en opción al grado científico de Doctor en Informática. Universidad de Granada, Spain.

10. MATA, F. 2006. Modelos para sistemas de apoyo al consenso en problemas de toma de decisión en grupo definidos en contextos lingüisticos multigranulares. Tesis presentada en opción al grado científico de Doctor en Informática. Universidad de Jaén. Jaén. 2006. 
11. DÍAZ CAZAÑAS, R. 2008. Modelo conceptual y Procedimiento general para el diagnóstico y mejoramiento del nivel de integración Operaciones-Mantenimiento. Tesis en opción al título de Máster en Gestión de la Producción. Universidad Central de Las Villas, Santa Clara, Cuba.

12. BORROTO PENTÓN, Y. 2005. Contribución al perfeccionamiento de la gestión de mantenimiento en instalaciones hospitalarias de segundo nivel asistencial. Aplicación en el Hospital Provincial Clínico Quirúrgico “Celestino Hernández Robau”. Tesis presentada en opción al grado científico de doctor en ciencias técnicas. Universidad Central de Las Villas, Santa Clara, Cuba.

13. COFRÉ GAJARDO, F. 2006. Modelos difusos para cuantificación del rendimiento laboral. Aportes para la construcción de un sistema inteligente de gestión de recursos humanos. Trabajo de tesis para sustentar el grado científico de Doctor en Informática. Universidad de Granada, Spain.

14. RUIZ, R., GARCÍA, C. and MAROTO, C. 2007. Considering scheduling and preventive maintenance in the flowshop sequencing problem. Computers \& Operations Research. 2007. 34. 3314-3330. 0305-0548.

15. AL-NAJJAR, B. 2006. The lack of maintenance and not maintenance which costs: A model to describe and quantify the impact of vibration - based maintenance on company's business. International Journal of Production Economics. 2006. 107. 260 - 273. 0925-5273.

\section{ORCID:}

Daynier Rolando Delgado Sobrino 0000-0001-9253-6141

Peter Koštál 0000-0001-6622-6174 